\title{
Progresos económicos, deudas estructurales y desigualdades sociales persistentes en la Argentina: 2003-2012*
}

\author{
Agustín Salvia*
}

El desempeño social de la Argentina en las últimas dos décadas ha estado asociado con dos modelos político-económicos diferentes. Por una parte, el período que va entre 1991 y 2001, dominado por la aplicación de reformas estructurales y políticas de apertura y liberalización económicas de inspiración neoliberal, junto con la aplicación de un programa antiinflacionario basado en un régimen de convertibilidad (tipo de cambio fijo en paridad con el dólar). En este marco, se logró controlar la situación de hiperinflación, acceder al crédito externo, equilibrar el gasto público, promover la inversión de capital y activar un ciclo de crecimiento económico. Como consecuencia de este proceso, si bien descendió inicialmente la pobreza, creció el desempleo, aumentó la precariedad laboral y se ampliaron las brechas de desigualdad social.

Pero a finales de la década, cuando no fue posible acceder al financiamiento externo, las restricciones monetarias estancaron la economía interna. El déficit fiscal y la abultada deuda pública acumulada emergieron una vez más como una seria restricción a las posibilidades de crecimiento. La inflexibilidad del modelo de estabilización de precios para adecuar los niveles de competitividad, sumado a la caída de los precios de los bienes primarios de exportación potenciaron la recesión. ${ }^{1}$

En este contexto, la puesta en marcha de medidas de ajuste agravó la situación, lo cual condujo en último término a declarar el default de la deuda a fines de 2001, a la salida del régimen de convertibilidad y a una fortísima devaluación a principios de

\footnotetext{
* El autor agradece la colaboración de María Hertelendy y Candela Pagnoni, asistentes de investigación del Programa del Observatorio de la Deuda Social Argentina, en la elaboración de este artículo.

* Agustín Salvia es Investigador Independiente del CONICET, Director del grupo Cambio Estructural y Desigualdad Social del Instituto Gino Germani de la Universidad de Buenos Aires e investigador jefe del Observatorio de la Deuda Social Argentina en el Departamento de Investigación Institucional de la UCA.

${ }^{1}$ De tal modo que modelo "pro-mercado" dejó entrever una alta volatilidad como producto, en parte, de la incapacidad del esquema de la convertibilidad para compensar shocks externos mediante la flexibilidad nominal que otorgara a la política monetaria y cambiaria (Damill et al., 2011).
} 
2002. El país enfrentó un colapso socioeconómico y político-institucional sin precedentes.

Sin embargo, los efectos regresivos de esta crisis comenzaron a diluirse rápidamente a finales de 2002. A partir de ese momento, bajo condiciones externas favorables, a través de políticas heterodoxas en materia salarial, cambiaria, monetaria y distributiva, se inició un período de sostenido crecimiento.

La devaluación modificó radicalmente el sistema de precios y el comportamiento macroeconómico, generando además de una caída en los salarios, un incremento sustantivo en el tipo de cambio real, una rápida respuesta exportadora y una creciente sustitución de importaciones; este proceso fue también favorecido por el incremento que experimentaron los precios de las exportaciones primarias en el mercado mundial. Todo esto generó una fuerte recuperación del nivel de actividad y del empleo, así como un creciente superávit comercial y fiscal. En este contexto, fue posible estabilizar la inflación, cancelar deudas y reactivar el consumo interno. En igual sentido operaron las políticas activas en materia de inversión pública, salario mínimo, negociaciones colectivas y jubilaciones, así como también la extensión de los programas sociales de transferencia de ingresos para familias sin empleo. Estas condiciones hicieron posible un aumento de los ingresos reales de los hogares, una disminución de la pobreza y una mejor distribución del ingreso.

A diferencia del régimen político-económico neoliberal, el modelo "neodesarrollista" bajo la administración analizada, introdujo un conjunto de dispositivos con el fin de regular el funcionamiento de los mercados. Este modelo ha continuado hasta el presente promoviendo -aunque no sin percances, desajustes y estancamientos-, el aumento del consumo interno, el mantenimiento del empleo, el aumento del gasto social y la disminución de la pobreza, aunque teniendo como correlato una creciente presión inflacionaria, un déficit fiscal en alza y una menor tasa de inversión interna.

Justamente, una vez que pasó la reactivación postcrisis, a partir de 2006-2007, sin acceso al financiamiento externo y recortado el financiamiento interno, el aumento de la oferta de bienes y servicios por debajo del crecimiento de la demanda agregada no tardó en generar un proceso inflacionario, junto a una creciente puja distributiva. Esto sumado a la decisión de servirse de esta situación para solventar el gasto público sin devaluación del peso, comenzó a generar una serie de desequilibrios en materia de balance comercial, retracción de la inversión, caída del nivel de actividad y de las expectativas cambiarias. Esto se expresó a nivel macroeconómico en una desaceleración del crecimiento, reducción del superávit comercial, aumento de precios internos y estancamiento del empleo. En este marco, no debe extrañar que tendieran a cristalizarse situaciones de marginalidad laboral, pobreza estructural y desigualdad social, así como tampoco que el gobierno haya necesitado ampliar los programas de 
asistencia y transferencia de ingresos con el doble objetivo de sostener el consumo interno y de dotar de estabilidad social al modelo político-económico.

Llegados a este punto, es evidente que este modelo en parte virtuoso en materia de crecimiento, consumo y movilidad social, resignó atender y resolver una serie de barreras estructurales para el desarrollo. En particular, cabe hacer referencia a los desajustes generados por la heterogeneidad en la productividad, la falta de integración de los mercados y el déficit de infraestructura e inversión en áreas claves para el desarrollo. ${ }^{2}$ En este contexto, la pregunta central que recorre este trabajo es ¿en qué medida las mejoras generadas en materia de consumo y bienestar por el régimen macroeconómico y las políticas sociales durante los últimos años fueron capaces de garantizar un desarrollo social más integral, sustentable y equitativo?

\section{Estrategia de estudio}

La hipótesis de trabajo que orienta este estudio es que el crecimiento económico, el aumento del consumo interno, el incremento de la demanda de empleo, la recuperación de los salarios de los trabajadores formales, la extensión de los programas sociales, e, incluso, la reducción de la indigencia y la pobreza por ingresos, no lograron constituirse en factores capaces de estructurar una vía de escape al subdesarrollo y la marginalidad social. Por el contrario, la tesis central es que tales procesos no solo no redujeron las desigualdades socioeconómicas estructurales fundadas en las condiciones productivas, la segmentación del mercado de trabajo y/o el origen de clase de la población, sino que han cristalizado aún más estas desigualdades y degradado las menguadas potencialidades de las instituciones político-ciudadanas para alterar de manera progresista la actual matriz de marginalidad social.

Esta tesis se fundamenta en el hecho de que el incremento del PBI de una nación no es incompatible con el sostenimiento o incluso el aumento de la desigualdad económica y de condiciones de heterogeneidad y exclusión social. Sin duda, la desigualdad estructural no es nueva. Su existencia constituye un rasgo que acompaña a la sociedad argentina desde hace al menos tres décadas, su conformación es la suma de factores tanto internos como externos. Pero ello no inhabilita la pregunta acerca de cuál ha sido el efecto del crecimiento económico y de las mejoras sociales promovidas durante el modelo "neodesarrollista" sobre el desarrollo humano y en relación al logro de una más equitativa distribución de las capacidades de integración social.

Obviamente, bajo esta perspectiva, la pobreza ya no puede ser asimilada

\footnotetext{
${ }^{2}$ A partir de lo cual resulta inevitable no caer en una de las clásicas "trampas de crecimiento" que imponen los modelos que dependen del sector externo para sostener un alto nivel de actividad y de consumo en el mercado interno (Salvia, 2011).
} 
exclusivamente a una situación de insuficiencia de ingresos, sino que debe entenderse como la imposibilidad de acceder a niveles fundamentales de realización humana, bienestar e integración social. Desde esta perspectiva (Tami y Salvia, 2005; Salvia, 2006; Salvia, 2011a), el mejoramiento del bienestar económico adquiere una función instrumental ${ }^{3}$ : solo si el aumento del ingreso deriva en una mayor, mejor y más equitativa dotación de las capacidades sociales (es decir, en un ejercicio efectivo de las actividades que permiten no solo garantizar la subsistencia, sino también potenciar el desarrollo socio-económico integral de las fuerzas productivas), se puede afirmar que se ha mejorado la calidad de vida. ${ }^{4}$

Al respecto, cabe agregar que si bien el crecimiento constituye un camino por demás favorable para el desarrollo, la falta de consensos sociopolíticos en el tipo de horizonte alternativo planteado tiende a poner barreras en este sentido. Por lo mismo, el diagnóstico sobre las capacidades de progreso en el mediano plazo, aunque económicamente promisorio, resulta todavía poco prometedor en el campo de la superación de las barreras estructurales que impiden una efectiva integración social. Es decir, el país muestra un escenario en donde no solo se carece de un plan de desarrollo y distribución real de las capacidades productivas y de integración social, sino que sobre todo no se percibe la emergencia de un espacio de debates y negociaciones político-institucionales para lograr tal resultado. ¿Podemos esperar que el crecimiento económico derrame por sí solo progresos sociales y gobernanza democrática perdurables en el tiempo? La experiencia histórica da cuenta de los contraproducentes efectos a los que lleva este supuesto.

En este marco, las dimensiones del desarrollo humano y social que se abordan en este trabajo de investigación no constituyen por sí mismas una expresión de las causas que generan este problema, sino, fundamentalmente, los espacios en donde es posible evaluar sus consecuencias. Tales características son también correas de transmisión que hacen posible la reproducción ampliada de las actuales condiciones de subdesarrollo económico, social, político y cultural que afectan a la sociedad.

Con el objetivo de contrastar la tesis propuesta y discutir estas perspectivas con base en la evidencia empírica, se utilizan en este artículo datos generados por la

\footnotetext{
${ }^{3}$ En otros términos, tal como sostiene la tradición teórica de los estudios del Observatorio de la Deuda Social, ni la estabilidad macroeconómica ni el aumento de los ingresos son sinónimos de mejor calidad de vida o de mayor integración social si tales procesos no están acompañados de realizaciones, funcionamientos y distribución de recursos que permitan una mejor y más equitativa estimulación de las capacidades de desarrollo humano y social de un país (Tami y Salvia, 2005; Salvia, 2006; Salvia, 2011a).

${ }^{4}$ No obstante, el enfoque de los ingresos resulta importante, en virtud de que la posibilidad de acceder a un conjunto de bienes y servicios en el marco de una economía de mercado dependerá en gran medida de la capacidad monetaria del hogar. La insuficiencia de ingresos tendrá entonces efectos sobre las posibilidades de los hogares de satisfacer un conjunto de necesidades esenciales para la subsistencia $y$, con ello, la posibilidad de desarrollo de otros funcionamientos humanos y sociales valiosos.
} 
Encuesta de la Deuda Social Argentina (EDSA) (Observatorio de la Deuda Social Argentina ODSA-UCA) para el período 2004-2012, empalmando para ello los resultados de la EDSA Serie Histórica (2004-2010) a los datos de la EDSA Serie Bicentenario (20102012). Lamentablemente las estadísticas oficiales no cuentan con la calidad y fiabilidad necesarias para evaluar con objetividad los problemas mencionados. Este hecho, aunque parezca secundario, no deja de ser un signo de los problemas que organizan la vida político-institucional de nuestro país. Más allá de la gravedad que tiene la falta de estadísticas sociales oficiales confiables, el hecho constituye una expresión de las dificultades que reviste en la Argentina actual consensuar políticas de Estado.

Actualmente, la EDSA se aplica de manera periódica a una muestra de hogares urbanos de diferentes regiones del país, lográndose con ello una importante representación urbana nacional. ${ }^{5}$

Si bien cabe reconocer que los indicadores que se analizan en este trabajo no agotan la evaluación de las capacidades de autonomía económica y de integración social de los hogares y de la población durante el período de estudio, ellos al menos posibilitan una aproximación mucho más amplia y robusta que las medidas indirectas de ingresos y/o pobreza por línea de pobreza para evaluar el problema de las persistentes desigualdades y las marginalidades estructurales en nuestro país.

\section{Capacidad de subsistencia de los hogares}

Es sabido que durante el período 2003-2007, el país experimentó un fuerte proceso de recuperación económica y de transformaciones en la participación del Estado en lo que hace a su matriz productiva, el mercado de trabajo, el rol regulatorio del Estado y la reconstitución del tejido social dañado con la crisis 2001-2002. Sin embargo, la economía comienza a evidenciar entre 2006-2008 signos de desaceleración e inestabilidad en las capacidades de crecimiento, alcanzando incluso una caída como efecto también de la crisis internacional en el año 2009. Pero una vez superado dicho período recesivo en 2010 y 2011 se retomaron los niveles previos de expansión, lo que se expresó en una recuperación del crecimiento y el consumo, en el marco de una mejora de las remuneraciones del sector formal y una ampliación de la cobertura previsional y de los programas de transferencia de ingresos dirigidos a los sectores más pobres. Sin embargo, esta evolución económica parece haber encontrado un nuevo

\footnotetext{
${ }^{5}$ Dada la prioridad que para este análisis tiene la comparación de cambios en el tiempo, los datos de los años 2004 y 2007, correspondientes a la EDSA - Serie Histórica (2004-2010), generados a partir de una muestra de 2.130 hogares, se ajustaron estadísticamente por medio de un coeficiente de empalme a los datos con la Encuesta de la Deuda Social Serie Bicentenario (2010-2012), la cual releva sistemáticamente a 5.700 hogares urbanos en diferentes áreas urbanas del país (Gran Buenos Aires, Gran Rosario, Gran Córdoba, Gran Mendoza, Gran Tucumán, Gran Salta, Gran Resistencia, Neuquén-Plottier, Mar del Plata, Paraná, La Rioja, San Juan, Zárate, San Rafael, Comodoro Rivadavia y Ushuaia-Río Grande).
} 
freno en 2012-2013, no sin problemas adicionales en materia monetaria, fiscal y distributiva. En el Cuadro 1 se presenta una serie de datos de distintas fuentes que describen a grandes trazos la evolución de la década.

Cuadro 1. Evolución de indicadores económicos y de la pobreza en la argentina. Años: 2003, 2007, 2010 y 2012.

\begin{tabular}{|c|c|c|c|c|}
\hline & 2003 & 2007 & 2010 & 2012 \\
\hline PBI por habitante $\left(\right.$ Var. $\%$ anual) ${ }^{1}$ & 7,8 & 7,6 & 8,1 & 1,9 \\
\hline 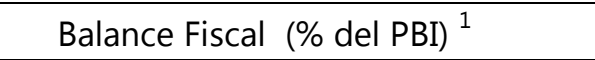 & 0,5 & 1,1 & 0,2 & $-1,0$ \\
\hline Gasto social $\left(\%\right.$ del PBI) ${ }^{1}$ & 10,1 & 10,3 & 13,1 & 15,3 \\
\hline Tasa anual de inflación ${ }^{2}$ & 13,4 & 18,5 & 22,4 & 25,9 \\
\hline Tasa de desocupación ${ }^{3}$ & 14,5 & 7,5 & 7,3 & 6,9 \\
\hline Tasa de subocupación ${ }^{3}$ & 16,3 & 9,1 & 8,3 & 9,0 \\
\hline $\begin{array}{l}\text { Mediana del ingreso laboral (\$ Dic. } \\
\text { 2013) }{ }^{4}\end{array}$ & 1981 & 3048 & 3138 & 3587 \\
\hline $\begin{array}{l}\text { Mediana ingreso per cápita de los } \\
\text { hogares }{ }^{4}\end{array}$ & 1351 & 1829 & 1883 & 2050 \\
\hline $\begin{array}{l}\text { Índice de Gini, ingreso per cápita } \\
\text { familiar de la población. }{ }^{4}\end{array}$ & 0,525 & 0,472 & 0,439 & 0,429 \\
\hline $\begin{array}{l}\text { Hogares que reciben programas } \\
\text { sociales (\% de hogares urbanos) }{ }^{5}\end{array}$ & 12,4 & 10,2 & 19,8 & 23,5 \\
\hline
\end{tabular}

${ }^{1}$ Base de datos del Banco Mundial - http://datos.bancomundial.org/indicador con datos del Ministerio de Economía de la Nación.

${ }^{2}$ Los datos de 2003 y 2007 corresponden al informe del IPC del INDEC, en tanto los datos de 2010 y 2012 constituyen un promedio de las tasas elaboradas por CENDA, FIEL e IPC- Facultad de Ciencias Económicas de la UBA.

${ }^{3}$ Mercado de trabajo: Principales indicadores. Informes de prensa de la Encuesta Permanente de Hogares del INDEC, Ministerio de Economía de la Nación.

${ }^{4}$ Evolución de la Distribución del Ingreso. Informes de prensa de la encuesta Permanente de Hogares del INDEC, Ministerio de Economía de la Nación.

${ }^{5}$ Encuestas de la Deuda Social Argentina (2004, 2007, 2010 y 2012). Observatorio de la Deuda Social Argentina, UCA.

Fuente: Elaboración propia, Observatorio de la Deuda Social Argentina. UCA.

El comportamiento del PBI per cápita para los años de la década considerados en el análisis, da cuenta de las tasas extraordinarias de crecimiento registradas en la economía argentina entre 2003 y 2010 -salvo la caída generada por la crisis internacional de 2009-. Esta tendencia se mantuvo incluso hasta el año 2011, pero tal como muestra el Cuadro 1, en el año 2012 -incluso en 2013- la economía registró una importante retracción en el ritmo de crecimiento. Esto tuvo un impacto directo sobre la desocupación y la subocupación, las cuales cayeron entre 2003 y 2007 de 14,5\% y $16,3 \%$ a $7,5 \%$ y $9,1 \%$, respectivamente. Sin embargo, a partir de ese momento, la evolución del crecimiento -incluido el efecto crisis 2009- parece haber puesto un piso a esta tendencia. Desde 2007 hasta 2012, las tasas de desocupación y subocupación se 
mantuvieron sin cambios significativos, dejando al $16 \%$ de la población económicamente activa en situación de déficit de empleo.

En paralelo, la tasa anual de inflación, la cual tendió a mantenerse alrededor del 10\% entre 2003-2006, trepó a 18,5\% en 2007, a 22,4\% en 2010 y a 25,9\% en 2012. Debido tanto a la política laboral como a la dinámica del empleo y al efecto inflacionario, las medianas del ingreso de la ocupación principal y del ingreso per cápita de los hogares, si bien tuvieron una fuerte recuperación entre 2003 y 2007, desaceleraron su crecimiento en los años subsiguientes, especialmente entre 2007 y 2010.

Ante este estado de situación, el gasto social tuvo claramente una función compensatoria de la parálisis de la demanda de empleo y del aceleramiento del índice de precios. Luego de mantenerse en alrededor del 10\% del PBI entre 2003 y 2007, trepó al $13,1 \%$ y 15,3\% en 2010 y 2012, respectivamente. En este marco, destaca el particular crecimiento que experimentaron los programas sociales de empleo y/o transferencia condicionada de ingresos, los cuales pasaron de cubrir alrededor del $12 \%$ de los hogares entre 2003-2007, a brindar asistencia al 19,8\% y al 23,5\%, en 2010 y 2012, respectivamente. ${ }^{6}$ Al mismo tiempo, después de un superávit fiscal inicial que llegó hasta el $1,1 \%$ del PBI en 2007, este aporte tendió a decrecer a partir de ese momento hasta ser negativo en $2012(-1 \%)$.

Una mención aparte merece el análisis de la evolución que experimentó el tradicional índice de desigualdad de Gini. Según lo informado por el INDEC, este coeficiente medido para el total de ingresos per cápita familiar registró una caída importante a lo largo de todo el período. Un hecho que en efecto, más allá de alguna posible adulteración de datos, tiende a confirmarse por diferentes fuentes: la distribución del ingreso se hizo más equitativa debido sobre todo a un aumento de la participación en la torta de ingresos por parte de los sectores medios y el segmento más pobre de hogares. ${ }^{7}$ Sin embargo cabe hacer algunos reparos: a) la medición de la distribución del ingreso familiar y por medio de encuestas de hogares no registra la concentración de ingresos que logra la cúpula político-económica más rica y poderosa de la sociedad; b) en igual sentido cabe señalar que hay indicios ciertos acerca de que durante la década, sobre todo a partir de 2006-2007, tuvo lugar un aumento de la "no respuesta" y/o "subdeclaración" de ingresos por parte de los hogares más ricos de la

\footnotetext{
${ }^{6}$ La disminución porcentual observada en 2007 se explica a partir de la reducción de beneficiarios del Programa Jefes/as de Hogar Desocupados en el marco del proceso de recuperación económica iniciado en 2003. Pero esta tendencia se invirtió en el año 2010, a partir de la introducción a finales del 2009 del sistema de Asignación Universal por Hijo para desocupados y trabajadores informales.

${ }^{7}$ De todos modos cabe destacar que, según el INDEC, en 2012 -a nivel promedio anual- el 10\% de la población con más bajos ingresos concentraba el 1,6\% del ingreso total declarado; mientras que el 10\% más rico participaba del 31,2\% de esa misma torta. Esto datos contrastan de manera positiva con la situación en el período 2003-2004, inmediatamente posterior a la crisis 2001-2002: $1 \%$ y 35,2\%, respectivamente (ver

http://www.indec.gov.ar/nuevaweb/cuadros/4/eph_ing_total_cuadro3.xls).
} 
estructura social a los que acceden las encuestas de hogares (empleadores, profesionales independientes, directivos de empresas intermedias, etc.); y c) no debe excluirse la posibilidad de que a partir de la intervención del INDEC (diciembre 2006), haya tenido lugar una manipulación de los datos de ingresos correspondientes sobre todo a los sectores más pobres.

Ahora bien, desde una perspectiva integral del desarrollo -que no lo restringe al mero crecimiento de los indicadores macroeconómicos o de ingresos- cabe interrogarse: ¿en qué medida las mejoras de bienestar generadas por el crecimiento económico, el aumento del empleo y las políticas sociales durante la última década significaron un efectivo proceso de superación de privaciones estructurales que afectan las capacidades de inclusión social de los hogares? En esta línea, no solo es importante el examen de los niveles objetivos de ingreso, sino también de sus efectos directos sobre la subsistencia económica. En función de atender este problema se examina a continuación el comportamiento seguido - para los años tomados como ventana- por los indicadores de pobreza e indigencia por la línea de pobreza, pobreza por NBI, vivienda precaria, inseguridad alimentaria, autopercepción de suficiencia de ingresos y capacidad de ahorro de los hogares urbanos.

En el Cuadro 2 se presentan los datos de los estudios de la EDSA sobre los hogares particulares con el fin de analizar y evaluar una primera serie de indicadores socioeconómicos relevantes.

Cuadro 2. Indicadores de pobreza y subsistencia socioeconómica de los hogares. EDSA total urbano. Años: 2003 (2004), 2007, 2010 y $2012^{1}$ en porcentajes.

\begin{tabular}{|c|c|c|c|c|c|}
\hline & $2003(4)$ & 2007 & 2010 & 2012 \\
\hline \multirow{2}{*}{$\begin{array}{c}\text { Tasa de } \\
\text { Indigencia }^{4}\end{array}$} & Hogares & 17,8 & 7,2 & 4,3 & 2,8 \\
\hline & Personas & 24,1 & 10,0 & 7,5 & 4,9 \\
\hline \multirow{2}{*}{$\begin{array}{l}\text { Tasa de } \\
\text { Pobreza }{ }^{4}\end{array}$} & Hogares & 39,6 & 21,2 & 19,6 & 17,5 \\
\hline & Personas & 50,9 & 29,2 & 27,6 & 24,5 \\
\hline \multicolumn{2}{|c|}{ Hogares con ingresos insuficientes ${ }^{2}$} & 53,3 & 33,5 & 33,4 & 34,1 \\
\hline \multicolumn{2}{|c|}{ Hogares con capacidad de ahorro ${ }^{3}$} & 7,5 & 17,3 & 15,9 & 15,3 \\
\hline \multicolumn{2}{|c|}{$\begin{array}{l}\text { Hogares con inseguridad } \\
\text { alimentaria }{ }^{4}\end{array}$} & 23,0 & 12,3 & 12,2 & 11,7 \\
\hline \multicolumn{2}{|c|}{ Hogares en viviendas precarias ${ }^{5}$} & 6,9 & 6,4 & 5,9 & 5,6 \\
\hline \multicolumn{2}{|c|}{ Hogares con $\mathrm{NBI}^{6}$} & 15,7 & 12,3 & 11,7 & 11,3 \\
\hline
\end{tabular}

${ }^{1}$ Con el objetivo de hacer comparables los datos de la EDSA Bicentenario 2010-2012 con serie anterior (EDSA 2004-2010), los datos correspondientes a 2004 y 2007 fueron ajustados por un coeficiente de empalme con base en el año 2010.

${ }^{2}$ Hogares que declaran que sus ingresos corrientes no les permiten cubrir sus gastos mensuales y sostener patrones de consumo.

${ }^{3}$ Hogares que declaran que los ingresos corrientes les permite ahorrar más allá del consumo realizado. 
${ }^{4}$ Hogares que declaran no haber podido acceder a una dieta alimentaria suficiente $\mathrm{o}$, incluso, haber registrado eventos de hambre por motivos económicos de manera regular o con relativa frecuencia durante los últimos 12 meses.

${ }^{5}$ Hogares que corresponden a las categorías de piezas de inquilinato, ranchos, casillas, hogares en casa de inquilinato, locales no construidos para habitación y viviendas móviles.

6 Hogares que presentan al menos una de las siguientes situaciones: 1- más de tres personas por cuarto habitable; 2- habitar una vivienda de tipo inconveniente (pieza en inquilinato, vivienda precaria); 3 - hogares sin ningún tipo de retrete; 4- hogares con algún niño en edad escolar (6 a 12 años) que no asiste a la escuela; 5 - hogares con cuatro o más personas por miembro ocupado $y$, además, cuyo jefe tuviera como máximo hasta primaria completa.

Fuente: EDSA 2004-2010 ( $n=2.100$ hogares) y EDSA-Bicentenario 2010-2016 ( $n=5.700$ hogares), Observatorio de la Deuda Social Argentina, UCA.

En primer lugar, cabe observar que el análisis de las tasas de indigencia y pobreza medidas en 2003 por la EPH-INDEC y para el resto de los años por la EDSA-ODSAmuestra la evidente mejora ocurrida en materia de bienestar en ambas tasas entre 2003 y 2007, a la vez que a partir de ese año la evolución -aunque continúa siendo positivamuestra una creciente desaceleración, lo cual se explica fundamentalmente debido al estancamiento del empleo, al aumento de la inflación y a la retracción económica de los últimos años. A pesar de esto, la pobreza -y sobre todo la indigencia- continuaron cayendo, debido mayormente al efecto positivo que tuvieron primero el aumento de las remuneraciones seguido del aumento del gasto social (por vía de la asistencia previsional y la Asignación Universal por Hijo). De todos modos, a finales de 2012 la indigencia y la pobreza medidas por ingresos todavía afectaban al 4,9\% y 24,5\% de la población, respectivamente.

En este sentido cabe destacar que no todos los indicadores de bienestar tuvieron durante el último período el mismo comportamiento. En primer lugar, tomando la percepción o denuncia de ingresos insuficientes por parte de los hogares -aunque se trata de una medida relativa-, en 2004, más de la mitad de los hogares urbanos declararon estar en déficit. Durante los tres años siguientes este porcentaje disminuyó en 20 puntos porcentuales, pasando de un 53,3\% a un 33,5\%. Sin embargo, en correspondencia con el aumento inflacionario, esta cifra apenas varió a lo largo del período 2007-2012. Desde 2007, casi sin cambios, 34 de cada 100 hogares declaran no contar con los ingresos suficientes para hacer frente a las necesidades económicas cotidianas. En el otro extremo, algo similar ha ocurrido con la capacidad económica de ahorro. Mientras que en 2004 , solo un $7,5 \%$ de los hogares urbanos podían destinar una parte de sus ingresos para ahorrar, en 2007, esta capacidad mejoró en 10 puntos porcentuales. Sin embargo, a partir de ese año, el indicador se estancó en alrededor de un $15 \%$.

En estrecha correspondencia con estos indicadores, entre 2004 y 2007, la 
inseguridad alimentaria -hogares afectados por reducción de la dieta alimentaria básica o eventos de hambre por razones económicas- disminuyó en forma abrupta, pasando de un $23,0 \%$ a un $12,3 \%$ en menos de tres años. Pero a partir de ese momento, aunque la tendencia siguió siendo decreciente (11,7\% en 2012), la reducción dejó de ser significativa.

En igual sentido, cabe observar que en 2004 los hogares pobres medidos por Necesidades Básicas Insatisfechas representaban el 15,7\% del total de hogares urbanos. Tres años después, en 2007, este déficit cayó a 12,8\%, mostrando una vez más el impacto social de la recuperación económica. Sin embargo, a partir de ese momento, las mejoras dejaron de ser tan relevantes, hasta llegar en 2012 a una tasa de NBI del $11,3 \%$ de hogares. Al mismo tiempo, si bien la tendencia en el porcentaje de viviendas precarias fue decreciente a lo largo de toda la década (de 6,9\% en 2004 a 5,6\% en 2012), las mejoras resultaron poco relevantes en comparación con la evolución de los demás indicadores socioeconómicos.

\section{Situación laboral y calidad del empleo}

El trabajo constituye algo más que un medio para satisfacer las necesidades materiales de una población: como actividad exclusivamente humana, es también un factor de desarrollo personal, de socialización, de reconocimiento social, de participación en la generación de un producto social y de la constitución de identidad colectiva. Consecuentemente, la imposibilidad de acceder a un empleo o hacerlo en condiciones desfavorables y no contar con protección social constituyen hechos que alteran la dignidad de las personas, que afectan su salud psicofísica y que violan derechos reconocidos en instancias internacionales y nacionales. ${ }^{8}$

El tipo y la calidad de la inserción laboral de la fuerza de trabajo constituye un indicador clave para evaluar las capacidades de desarrollo y convergencia del modelo político-económico neodesarrollista vigente desde 2003 hasta el presente. Con base en este parámetro, cabe observar que en líneas generales, entre los años 2004 y 2010 es fácil hacer un balance positivo en materia laboral, lo que se evidencia a través de un aumento de la tasa de empleo en general, así como también en una disminución de la subocupación y la desocupación. Sin embargo, estas mejoras no se verificaron con la misma calidad e intensidad para el conjunto de la población económicamente activa según su posición en la estructura social.

Con el fin de explicitar los hechos a los que se hace referencia, en el Cuadro 3.1 puede verse la evolución laboral 2004-2007-2010-2012 a nivel general y para los segmentos superior e inferior de la estratificación socioeducativa de los hogares.

\footnotetext{
${ }^{8}$ Véase el capítulo 3 de las publicaciones de 2011 y 2012 del Barómetro de la Deuda Social (Donza, 2011 y 2012).
} 
Asimismo, en el Cuadro 3.2 se informa sobre la evolución de los ingresos laborales a precios constantes por tipo de inserción laboral.

Cuadro 3.1. Inserción laboral y protección social de la población económicamente activa (18 años y más). EDSA total urbano. Años: 2004, 2007, 2010 y 2012. ${ }^{1}$ en porcentajes.

\begin{tabular}{|c|c|c|c|c|c|}
\hline & & 2004 & 2007 & 2010 & 2012 \\
\hline \multirow[t]{4}{*}{ Empleo Total } & Total & 83,3 & 89,6 & 88,8 & 91,6 \\
\hline & (1) Muy Bajo & 73,6 & 70,9 & 78,1 & 83,7 \\
\hline & (2) Medio - Alto & 94,4 & 96,6 & 96,0 & 96,8 \\
\hline & Ratio (1) / (2) & 0,78 & 0,73 & 0,81 & 0,86 \\
\hline \multirow{4}{*}{ Empleo Pleno } & Total & 30,1 & 46,8 & 44,5 & 45,0 \\
\hline & (1) Muy Bajo & 10,1 & 15,0 & 13,0 & 12,4 \\
\hline & (2) Medio - Alto & 41,2 & 68,4 & 67,2 & 71,8 \\
\hline & Ratio (1) / (2) & 0,24 & 0,22 & 0,19 & 0,17 \\
\hline \multirow{4}{*}{$\begin{array}{l}\text { Empleo } \\
\text { Precario }\end{array}$} & Total & 38,1 & 32,1 & 35,3 & 35,3 \\
\hline & (1) Muy Bajo & 46,5 & 39,4 & 43,4 & 40,7 \\
\hline & (2) Medio - Alto & 37,8 & 27,0 & 28,0 & 23,8 \\
\hline & Ratio (1) / (2) & 1,2 & 1,46 & 1,55 & 1,71 \\
\hline \multirow{4}{*}{$\begin{array}{l}\text { Subempleo } \\
\text { Inestable }\end{array}$} & Total & 15,1 & 10,7 & 9,0 & 11,3 \\
\hline & (1) Muy Bajo & 26,6 & 16,5 & 21,7 & 30,6 \\
\hline & (2) Medio - Alto & 3,8 & 1,2 & 0,8 & 1,2 \\
\hline & Ratio (1) / (2) & 7 & 13,6 & 27,13 & 25,5 \\
\hline \multirow{4}{*}{ Desempleo } & Total & 16,7 & 10,4 & 11,2 & 8,4 \\
\hline & (1) Muy Bajo & 26,4 & 29,1 & 21,9 & 16,3 \\
\hline & (2) Medio - Alto & 5,6 & 3,4 & 4,0 & 3,2 \\
\hline & Ratio (1) / (2) & 4,71 & 8,56 & 5,48 & 5,10 \\
\hline \multirow{4}{*}{$\begin{array}{c}\text { Trabajadores } \\
\text { sin Seguridad } \\
\text { Social }\end{array}$} & Total & 54,4 & 47,0 & 47,2 & 49,4 \\
\hline & (1) Muy Bajo & 84,2 & 82,4 & 79,8 & 83,7 \\
\hline & (2) Medio - Alto & 33,2 & 27,6 & 26,6 & 24,2 \\
\hline & Ratio (1) / (2) & 2,54 & 2,99 & 3,0 & 3,46 \\
\hline
\end{tabular}

${ }^{1}$ Con el objetivo de hacer comparables los datos de la EDSA Bicentenario 2010-2012 con la serie anterior (EDSA 2004-2010), los datos correspondientes a 2004 y 2007 fueron ajustados por un coeficiente de empalme con base en el año 2010.

Fuente: EDSA 2004-2010 ( $n=2.100$ hogares) y EDSA-Bicentenario 2010-2016 ( $n=5.700$ hogares), Observatorio de la Deuda Social Argentina, UCA.

Empleo pleno de derechos. Tuvo lugar entre los años 2004 y 2007, después de la crisis 2001-2002, momento en que el país experimentó una importante recuperación económica, la cual impactó de manera directa tanto en el aumento de la tasa general de empleo como en su calidad. En este sentido, cabe observar que la tasa de empleo 
total pasó de 83,3\% a 89,6\% entre 2004 y 2007, aunque tendió a retraerse en 2010, para volver a crecer a $91,6 \%$ en 2012 . En términos de la estratificación social, los datos confirman que el empleo creció entre puntas del período de manera algo más dinámica en el segmento más pobre de la estructura social.

Pero esta tendencia esconde evoluciones muy diferentes dependiendo del tipo de empleo que se considere. Al respecto, el denominado empleo pleno de derechos tuvo un importante crecimiento, entre 2004 y 2007, de 30,1\% a 46,8\%. A partir de ese momento, pasada la crisis nacional e internacional de 2009 , la tasa de empleo pleno tendió a retraerse levemente, de tal modo que a finales de 2012 , solo el $45 \%$ de la fuerza de trabajo urbana disponía de un empleo productivo pleno de derechos.

Ahora bien, esta evolución positiva no parece haber alterado la desigual distribución de las oportunidades de empleo. Después del estancamiento ocurrido, entre 2007 y 2010, en el ritmo de creación de empleos plenos en el segmento superior, la posibilidad de acceso a un empleo de este tipo para este grupo volvió a subir en 2012, alcanzando una tasa del 71,8\% (acumulando un incremento del 75\% entre 2004 y 2012). Esta evolución contrasta tanto a nivel absoluto como relativo con lo ocurrido en el segmento inferior, en donde pasado el importante crecimiento logrado entre 2004 y 2007, la tasa de empleo pleno en este grupo cayó tanto en 2010 como en 2012, hasta llegar al $12,4 \%$ en ese último año (acumulando un incremento de solo el $22 \%$ ).

Empleo precario. Al considerar el empleo precario - sea asalariado o no asalariado (donde no se cumple la afiliación social pero se posee regularidad laboral con ingresos mínimos de subsistencia)- se observa una correspondencia con la evolución del empleo pleno. Al respecto, destaca el hecho de que el empleo precario cayó de 38,1\% a $32,1 \%$ entre 2004 y 2007 , pero a partir de ese año tiende nuevamente a crecer hasta alcanzar al 35,3\% de la PEA urbana en 2012.

Al considerar la estratificación social también se confirma la desigual tendencia que experimentó este indicador. Por una parte, la caída fue más abrupta y permanente en el segmento socioeducativo superior (pasó de 37,8\% a 23,8\% entre 2004 y 2012); mientras que en el estrato inferior la mayor generación de empleo se tradujo en un aumento del empleo de este tipo, el cual pasó de 36,9\% a 40,7\% durante igual período. De este modo, la brecha de oportunidades laborales entre ambos segmentos pasó a ser regresiva y a crecer de manera constante a lo largo de la década.

Subempleo inestable/Desempleo. Al considerar la tasa de subempleo inestable (trabajos de muy baja remuneración, sin protección social y alta inestabilidad), como efecto del aumento del empleo, se observa una fuerte caída entre 2004 y 2007, aunque luego le sigue un cierto estancamiento y posterior ascenso. En efecto, este indicador pasa de $15,1 \%$ a $9 \%$ entre 2004 y 2010, para subir a 11,3\% en 2012. Pero al evaluar la evolución de este tipo de inserción marginal por estrato social, cabe destacar que si 
bien se redujo inicialmente la prevalencia del mismo en los extremos sociales, esta forma de subsistencia se duplicó entre 2007 y 2012 en el segmento más bajo de la estratificación social (pasó de 16,5\% a 30,6\%), a la vez que se mantiene casi sin cambios en $1,2 \%$ en el estrato superior. De este modo, la brecha de desigualdad social aumentó durante todo el período, esto como resultado de un crecimiento económico que concentró empleos de indigencia en los estratos estructuralmente más pobres.

Como extensión de este proceso, dada la evolución general registrada por la tasa de empleo y la precariedad laboral, la desocupación abierta cayó durante el período 20042012 de 16,7\% a 8,4\%. Sin embargo, aquí también el porcentaje de población desempleada siguió una evolución desigual según el estrato social de pertenencia. Por una parte, la probabilidad de estar desocupado disminuyó de $26,3 \%$ a $16,3 \%$ en el estrato más bajo, $y$, al mismo tiempo, también se redujo -aunque desde niveles muy diferentes- de 5,6\% a 3,2\% en el estrato medio alto. Como resultado de esta tendencia, la brecha social de desempleo no sólo no cayó sino que aumentó a lo largo del período.

Trabajadores sin seguridad social. La contribución de trabajadores al sistema de la Seguridad Social -sean asalariados o no- asegura tanto un servicio de salud presente como un ingreso a futuro en concepto de jubilación. En el caso de los empleados en relación de dependencia esta vinculación implica además otros importantes beneficios (seguro de desempleo, salario familiar, licencias especiales, etc.). ${ }^{9}$ La ausencia de tales contribuciones lleva a la exclusión de los beneficios laborales y sociales mencionados y requiere de esfuerzos sociales adicionales por parte del Estado.

El análisis de la evolución entre 2004 y 2012 de la tasa de trabajadores (asalariados y no asalariados) que no aportan al Sistema de la Seguridad Social también constituye entonces un buen indicador de la capacidad del sistema económico para generar o no buenos empleos para todos. Al respecto, cabe destacar que a pesar del aumento del empleo y de los programas de fiscalización laboral, promoción de políticas de blanqueo y moratorias contributivas desarrolladas desde el Estado, los índices de trabajo no registrado continuaron siendo relativamente elevados.

Entre los años 2004 y 2012 los trabajos sin participación en el sistema de la seguridad social disminuyeron solo de $54,4 \%$ a $49,4 \%{ }^{10}$ (incluyendo tanto asalariados como cuentapropistas y patrones o empleadores). A igual que en otros indicadores de calidad de los empleos, la mayor caída tuvo lugar entre 2004 y 2007 (47\%), para luego estancarse en 2010 (47.2\%) y volver a subir en 2012 (49,4\%).

\footnotetext{
${ }^{9}$ En el caso de los trabajadores por cuenta propia y patrones o empleadores, la participación en la seguridad social también conlleva ventajas que trascienden el cumplimiento de obligaciones contributivas. El no participar los excluye de la asistencia de una obra social y de una futura jubilación.

${ }^{10}$ Cabe aclarar que estos datos señalan una disminución bastante menor al que señalan las cifras oficiales provenientes del INDEC.
} 
Considerando la variación entre 2004 y 2012 de la falta de participación de los trabajadores con aportes al sistema según su ubicación en la estructura social, la mayor mejora se registró en el estrato social medio alto, pasando este déficit de 33,2\% a 24,2\% entre los años extremos de la serie, mientras que simultáneamente, más allá de algunas mejoras parciales ocurridas en 2007 y 2010, esta tasa no registró cambios significativos entre los trabajadores del estrato más pobre, pasando de $84,2 \%$ a $83,7 \%$, lo que en los hechos implicó un agravamiento mayor de la inequidad social.

\section{Media de ingresos laborales}

Si bien los derechos nacionales e internacionales expresan la necesidad de que el trabajo se retribuya en forma justa y con igual remuneración ante igual tarea, no siempre esto se encuentra debidamente garantizado. La variación en los niveles de ingreso de los trabajadores se debe, entre otras cuestiones, a la evolución general de la economía, diferenciales de productividad del empleo, atributos personales, escalafones laborales, capacidad de negociación colectiva, oferta y demanda de prestaciones, discriminaciones de género o de otro tipo, etc. Por otra parte, el ingreso laboral neto tiene efectos directos sobre la situación económica y la calidad de vida de la mayoría de los hogares, así como sobre la desigualdad al interior de la estructura social.

Uno de los factores que en nuestro país continúa afectando de manera injusta los ingresos de los trabajadores es la inflación. De ahí que, en función de examinar los cambios, ciclos y disparidades ocurridas en materia de remuneraciones entre 2004 y 2012 a nivel de los trabajadores urbanos del país, se analiza el comportamiento de los ingresos laborales controlando las variaciones que experimentaron los precios, utilizando para ello el IPC del INDEC en 2004 y un IPC alternativo no oficial para los años 2007, 2010 y 2012, elaborado por el Centro de Estudios para el Desarrollo Argentino (CENDA). 
Cuadro 3.2 Ingreso laboral neto según inserción laboral de los ocupados (18 años y más). EDSA total urbano. Años: 2004, 2007, 2010 y 2012. ${ }^{1}$ en pesos de diciembre de 2012.

\begin{tabular}{|c|l|c|c|c|c|}
\hline & & 2004 & 2007 & 2010 & 2012 \\
\hline & Total & 2.545 & 3.893 & 3.982 & 4.127 \\
\cline { 2 - 6 } & (1) Empleo pleno & 3.106 & 4.978 & 5.004 & 5.215 \\
Ingresos & (2) Empleo precario & 2.369 & 3.362 & 3.236 & 3.533 \\
laborales según & (3) Subempleo & & & & \\
Calidad de & inestable & 954 & 1.713 & 1.850 & 1.757 \\
empleo. & Ratio (1) / (2) & 1,3 & 1,5 & 1,5 & 1,5 \\
& Ratio (1)/(3) & 3,2 & 2,9 & 2,7 & 3,0 \\
\hline
\end{tabular}

${ }^{1}$ Con el objetivo de hacer comparables los datos de la EDSA Bicentenario 2010-2012 con serie anterior (EDSA 2004-2010), los datos correspondientes a 2004 y 2007 fueron ajustados por un coeficiente de empalme con base en el año 2010.

Fuente: EDSA 2004-2010 ( $n=2.100$ hogares) y EDSA-Bicentenario 2010-2016 ( $n=5.700$ hogares), Observatorio de la Deuda Social Argentina, UCA.

Una primera observación que muestran los datos (Cuadro 3.2) es que el promedio de ingresos laborales reales aumentó más de un 60\% entre el 2004 y 2012 (de \$ 2.545 a $\$ 4$.127). En efecto, esta evolución se explica fundamentalmente por los cambios ocurridos entre 2004 y 2007, momento a partir del cual las remuneraciones solo crecieron un 6\% entre ese año y 2012 (de $\$ 3.893$ a $\$ 4.127$ ). De esta manera se constata que el mayor incremento en las remuneraciones reales tuvo lugar durante los primeros años de reactivación económica, los cuales estuvieron acompañados por aumentos oficiales en el salario mínimo y un ejercicio creciente de las negociaciones colectivas. Sin embargo, esta tendencia sufrió un fuerte estancamiento debido a los aumentos que registraron los precios entre 2007 y la actualidad.

Ahora bien, los niveles de remuneración e, incluso, sus variaciones, presentan comportamientos muy distintos según el tipo de inserción laboral o calidad del empleo que se considere. Según se observa en el Cuadro 3.2, las remuneraciones medias netas a precios del 2012, no solo han sido marcadamente desiguales durante el período 2004-2012, sino que estas diferencias tendieron incluso a ampliarse a partir del 2007, manteniéndose sin cambios si se compara el comportamiento del empleo pleno de derechos con la categoría de empleo precario. El hecho permite inferir que a pesar de las mejoras observadas en las remuneraciones medias al interior de cada segmento, esta evolución, lejos de disolver, cristalizó las desigualdades estructurales y segmentaciones laborales que operan sobre la estructura productiva y el mercado de trabajo urbano. 


\section{Vivienda segura y hábitat de calidad}

Un aspecto fundamental en lo que hace a la calidad de vida de la población son las condiciones del hábitat urbano en las que esta se desenvuelve, entendiendo por tal al conjunto de componentes materiales y simbólicos que operan sistémicamente como marco de producción y reproducción cotidiana de las condiciones de vida y de sociabilidad. Sin embargo, no toda la sociedad ve satisfechas sus necesidades y realizados sus anhelos en la misma medida en los entornos urbanos. Mientras que una porción de la población cuenta con estándares de vida significativamente elevados, otra habita espacios hacinados y contaminados, padece hambre y sobrevive en condiciones de extrema precariedad.

En este sentido, la falta de condiciones adecuadas de hábitat no solo constituye un indicador de pobreza de recursos económicos sino también de equidad en la distribución de los recursos político-institucionales de inclusión social. En el marco de este apartado, interesa examinar en qué medida la recuperación económica global que tuvo lugar a partir de 2003 fue acompañada por análogas mejoras en las condiciones de hábitat de la población urbana. En igual sentido, cabe examinar en qué medida las inversiones -públicas o privadas- asociadas a la construcción de viviendas, desarrollo de infraestructura urbana y prestación de servicios domiciliarios, operadas en ese contexto, tuvieron efectos progresivos en materia de equidad e integración social para los hogares con residencia en las principales áreas urbanas del país.

Para ello, en las líneas que siguen se examina, para el período 2004-2007-20102012, una serie de dimensiones relevantes que hacen al desarrollo del hábitat urbano: el disfrute de una vivienda digna y segura, el usufructo de los servicios domiciliarios de red, el acceso a la infraestructura urbana básica y las condiciones medioambientales.

En el Cuadro 4 se encuentran los datos del estudio llevado a cabo por la EDSA sobre los hogares particulares con el fin de comparar y analizar los años en cuestión.

Tenencia irregular de la vivienda. La tenencia irregular de la vivienda es un indicador del déficit habitacional cuantitativo de nuestro país, y su permanencia en el tiempo expresa su carácter estructural. La falta de acceso a una vivienda propia incide en una variedad de aspectos que hacen a la calidad de vida de las personas, entre los que se encuentran factores emocionales como la seguridad y la posibilidad de proyectarse a largo plazo. En el año 2004, momento en el que aún se estaba saliendo de la crisis de $2001-2002$, el $15,0 \%$ de los hogares habitaba viviendas que no eran propias ni alquiladas, sino que presentaban distintas modalidades de tenencia irregular (ocupación de terreno o vivienda, vivienda en lugar de trabajo o préstamo, entre otras). Hacia 2007, en el contexto de los importantes logros económicos, laborales y sociales de la fase de recuperación, este déficit se redujo a 12,8\%. Sin embargo, a partir de ese 
momento esta tendencia parece haber encontrado un piso estructural $(13,5 \%$ en 2010 y $12,4 \%$ en 2012). ${ }^{11}$

Cuadro 4. Vivienda segura y hábitat de calidad (hogares particulares). Total urbano. Años: 2004, 2007, 2010 y 2012. ${ }^{1}$ en porcentajes.

\begin{tabular}{|c|l|c|c|c|c|}
\hline \multirow{4}{*}{$\begin{array}{c}\text { Tenencia } \\
\text { irregular de la } \\
\text { Vivienda }\end{array}$} & Total & $\mathbf{2 0 0 4}$ & $\mathbf{2 0 0 7}$ & $\mathbf{2 0 1 0}$ & $\mathbf{2 0 1 2}$ \\
\cline { 2 - 6 } & (1) Muy Bajo & $\mathbf{1 5 , 0}$ & $\mathbf{1 2 , 8}$ & $\mathbf{1 3 , 5}$ & $\mathbf{1 2 , 4}$ \\
\cline { 2 - 6 } & (2) Medio - Alto & 12,4 & 29,6 & 24,9 & 25,0 \\
\cline { 2 - 6 } & Ratio (1) / (2) & 2,3 & 3,0 & 7,0 & 4,0 \\
\hline \multirow{4}{*}{ Hacinamiento } & Total & $\mathbf{1 2 , 1}$ & $\mathbf{8 , 5}$ & $\mathbf{7 , 5}$ & $\mathbf{7 , 0}$ \\
\cline { 2 - 6 } & (1) Muy Bajo & 24,5 & 18,9 & 18,0 & 15,0 \\
\cline { 2 - 6 } & (2) Medio - Alto & 3,4 & 3,5 & 0,9 & 0,7 \\
\cline { 2 - 6 } & Ratio (1) / (2) & 7,2 & 5,4 & 19,3 & 21,3 \\
\hline \multirow{4}{*}{$\begin{array}{c}\text { Sin conexión a } \\
\text { red cloacal }\end{array}$} & Total & $\mathbf{4 2 , 3}$ & $\mathbf{3 8 , 0}$ & $\mathbf{3 5 , 9}$ & $\mathbf{3 4 , 1}$ \\
\cline { 2 - 6 } & (1) Muy Bajo & 68,7 & 66,9 & 65,7 & 61,3 \\
\cline { 2 - 6 } & (2) Medio - Alto & 10,0 & 9,7 & 8,2 & 8,1 \\
\cline { 2 - 6 } & Ratio (1) / (2) & 6,9 & 6,9 & 8 & 7,6 \\
\hline \multirow{3}{*}{$\begin{array}{c}\text { Sin conexión a la } \\
\text { red de gas }\end{array}$} & Total & $\mathbf{2 5 , 6}$ & $\mathbf{2 6 , 3}$ & $\mathbf{2 7}$ & $\mathbf{2 7 , 4}$ \\
\cline { 2 - 6 } & (1) Muy Bajo & 68,2 & 67,8 & 67,1 & 68,5 \\
\cline { 2 - 6 } & (2) Medio - Alto & 10,8 & 11,4 & 7,7 & 6,3 \\
\cline { 2 - 6 } & Ratio (1) / (2) & 6,3 & 5,9 & 8,7 & 10,9 \\
\hline \multirow{3}{*}{$\begin{array}{c}\text { Proximidad de } \\
\text { basurales o } \\
\text { fábricas }\end{array}$} & Total & $\mathbf{3 0 , 8}$ & $\mathbf{2 9 , 2}$ & $\mathbf{2 5 , 1}$ & $\mathbf{2 6 , 4}$ \\
\cline { 2 - 6 } contaminantes & (1) Muy Bajo & 43,3 & 38,1 & 37,6 & 39,6 \\
\cline { 2 - 6 } & (2) Medio - Alto & 13,1 & 16,0 & 12,6 & 14,7 \\
\cline { 2 - 6 } & Ratio (1) / (2) & 3,3 & 2,3 & 3,0 & 2,7 \\
\hline
\end{tabular}

${ }^{1}$ Con el objetivo de hacer comparables los datos de la EDSA Bicentenario 2010-2012 con serie anterior (EDSA 2004-2010), los datos correspondientes a 2004 y 2007 fueron ajustados por un coeficiente de empalme con base en el año 2010.

Fuente: EDSA 2004-2010 ( $n=2.100$ hogares) y EDSA-Bicentenario 2010-2016 ( $n=5.700$ hogares), Observatorio de la Deuda Social Argentina, UCA.

Al encontrarse este indicador estrechamente vinculado con la situación económica del hogar y con factores estructurales como la estratificación social, los datos evidencian que a pesar del crecimiento económico que nuestro país experimentó a lo largo de esos años, en el estrato socioeconómico más bajo la tenencia irregular descendió 3 puntos porcentuales, del 28,0\% al 25,0\% de los hogares. En tanto que el retroceso del indicador fue considerablemente más importante en las familias del segmento más alto de hogares (de $12,4 \%$ a 4,0\%), lo cual significó, más allá de las

\footnotetext{
${ }^{11}$ Se calcula que entre 2003 y 2012, la población en villas de emergencia o asentamientos precarios habría aumentado en términos absolutos en más de 250 mil hogares.
} 
mejoras generales, triplicar la brecha de desigualdad preexistente.

Hacinamiento. Una vivienda no solo debe proveer protección y abrigo a sus ocupantes, sino que también tiene que presentar las condiciones mínimas que permitan el desarrollo personal y la vida familiar en condiciones físicas y psicológicamente adecuadas. El hacinamiento medio, entendido como la condición en la que en una misma vivienda conviven (en promedio) 3 o más personas por cuarto habitable, constituye una característica adversa para el desarrollo antes referido. En nuestro país el hacinamiento es la resultante de la combinación de varios factores, entre los que se encuentra un déficit habitacional cuantitativo de naturaleza estructural producto de que el ritmo de crecimiento de la población sea más veloz que el de la construcción de unidades habitacionales. A su vez, también inciden factores coyunturales como la condición económica de un hogar que en etapas favorables permite aumentar la cantidad de habitaciones de la vivienda mientras que en períodos de retracción económica sucede lo inverso.

Como se muestra en el Cuadro 4 el hacinamiento en los grandes aglomerados urbanos de la Argentina se redujo significativamente entre los años 2004 y 2007 (de $12,1 \%$ a 8,5\%). Entre 2007 y 2012 volvió a reducirse hasta alcanzar el nivel más bajo de la serie, $7 \%$ de los hogares. Al ser el hacinamiento un indicador estrechamente vinculado con la capacidad económica del hogar, resulta relevante considerar las diferencias entre los distintos estratos sociales. Entre los años 2004 y 2012 el estrato inferior de los hogares redujo el hacinamiento un 39\% mientras que el estrato superior lo hizo en un $61 \%$, ubicándose respectivamente en $15,0 \%$ y $0,7 \%$ de los hogares en el último año de la serie, lo que implicó que la brecha entre ambos tipos de hogares se triplicara.

Déficit de conexión a la red cloacal. Junto con el acceso al agua potable mejorada, la conexión a desagües cloacales, que permiten una adecuada eliminación de residuos sólidos y líquidos, constituye un pilar fundamental en lo que refiere al saneamiento urbano. La falta de este servicio conduce a la presencia de aguas contaminadas como también a la diseminación de plagas, afectando gravemente la salud de la población. El bajo desarrollo del sistema cloacal ha sido uno de los rasgos más distintivos del déficit de servicios urbanos de nuestro país a lo largo de las últimas décadas.

Los datos de la EDSA muestran que el indicador de déficit comenzó a retroceder a partir del año 2007. Así, mientras que en 2004 afectaba al 42,3\% de los hogares, en 2007 alcanzaba al 38\% y en 2012 al 34,1\%.

Cuando se analiza la evolución del indicador según estrato social se verifican diferencias muy significativas. El déficit de conexión a la red en el estrato inferior siempre afectó al menos a seis de cada diez hogares. Así, en 2012 mientras que el $61,3 \%$ de los hogares del segmento inferior de la estratificación social carecía de 
conexión a la red, este problema afectaba solo al 8,1\% de las viviendas del segmento superior. Al mismo tiempo, cabe destacar que la brecha entre estratos sociales no solo no se redujo sino que tendió a incrementarse a lo largo de la década.

Déficit de acceso a red de gas. La disponibilidad de gas en red incide en forma directa tanto en el presupuesto familiar como en la calidad de vida de la población. Este recurso sigue siendo en la Argentina la principal fuente energética para la calefacción y la cocina de las viviendas. Sin embargo, a lo largo de la historia urbana del país, dentro del conjunto de los servicios domiciliarios de red, este ha sido uno de los menos extendidos y con la menor tasa de cobertura, con lo que los hogares sin acceso a él se han visto compelidos a abastecerse a través de otros medios como las garrafas, balones o tanques con gas comprimido (Arza, 2002; Banco Mundial, 2000).

La utilización de garrafas en lugar del gas natural a través de la red para la calefacción y la cocina de las viviendas particulares tiene consecuencias en la seguridad del hogar, a la vez que impacta negativamente en el presupuesto familiar. En lo que respecta al primer aspecto, mientras que los sectores más vulnerables utilizan las garrafas en condiciones poco seguras -en muchos casos en el interior de las viviendas-, los sectores socioeconómicos medios y altos que no acceden a la red generalmente no utilizan garrafas sino tubos y tanques en condiciones mucho más propicias -los contenedores se encuentran ubicados en el exterior del inmueble, las conexiones siguen estrictas normas de seguridad y por lo general el mantenimiento está a cargo de empresas especializadas. En cuanto al impacto económico en el presupuesto del hogar, la modalidad de acceso al gas es uno de los indicadores que ejemplifican con mayor crudeza la inequidad en la distribución de este recurso. Mientras que el precio para el consumidor final del gas por red ha sido subsidiado por años, no ha ocurrido lo mismo con el producto envasado, el cual es utilizado fundamentalmente por los estratos socioeconómicos más pobres. A su vez, al precio del producto -envasado o por red-se le suma el hecho de que para la conexión domiciliaria se requiere de un importante nivel de gasto previo que corre exclusivamente por cuenta de los usuarios. ${ }^{12}$

La evolución general de este indicador evidencia un retroceso importante entre los años 2004 y 2012, pasando del 25,6\% al 27,4\% de los hogares. Al mismo tiempo la brecha de déficit entre los estratos sociales mejor y peor posicionados no solo no se redujo sino que aumentó. Mientras que el porcentaje de hogares con déficit en el estrato social más alto disminuyó un $41.6 \%$ (pasó de 10,8\% a 6,3\%), en el segmento de hogares más pobres la situación no cambió manteniéndose un déficit cercano al $68 \%$.

\footnotetext{
${ }^{12}$ Cabe destacar que la relevancia del estudio del déficit de conexión a la red de gas se vincula estrechamente con la calidad del suministro de energía eléctrica, por cuanto ambos temas se inscriben en el debate sobre el estancamiento del desarrollo de la infraestructura energética del país durante la última década y sobre la ineficiencia generada por la política de subsidios.
} 
Esto implicó que la brecha entre ambos estratos en este problema particular llegara casi duplicarse durante ese período.

Basurales y fábricas contaminantes. Uno de los factores que tienen fuerte incidencia en el equilibro ambiental de una ciudad es la capacidad de gestionar y controlar los residuos sólidos que en ella se producen. En esto convergen diferentes agentes y aspectos tales como la regularidad y el tratamiento de los desechos sólidos, la disposición de contenedores en las áreas específicas, la educación, la cultura y las prácticas de los ciudadanos en lo que hace al cuidado del medio ambiente, entre otros. La existencia y proliferación de basurales es una de las consecuencias de un funcionamiento deficiente y desarticulado de estos componentes. A las deficiencias en los procesos de tratamiento de los residuos sólidos urbanos se suma la depredación del medio ambiente llevada a cabo por muchas empresas que, guiadas por una lógica de explotación del ambiente con fines lucrativos, no cumplen con las pautas mínimas de cuidado medioambiental, contribuyendo al incremento de los niveles de contaminación de las ciudades.

El deterioro de las condiciones medioambientales en las que vive una comunidad incide en forma directa sobre la calidad de vida de la población. Los basurales en las inmediaciones de una vivienda implican mayores riesgos de proliferación de plagas y de contaminación del suelo. Las fábricas que no acatan las políticas ambientales representan mayores posibilidades de elevación de los niveles de monóxido de carbono en el aire, de plomo en el agua, de desechos químicos en el suelo, entre tantos otros ejemplos.

De los datos de la EDSA se desprende que los basurales y las fábricas contaminantes en las inmediaciones de las viviendas se redujeron entre 2004 y 2010 de 30,8\% a 25,1\%, no experimentando luego cambios hasta 2012 (26,4\%). Si bien la prevalencia de este tipo de riesgo ambiental se redujo en un $14,2 \%$ entre los años extremos de la serie, el análisis de la evolución del indicador según estratos sociales da cuenta de que los más afectados continuaron siendo los hogares del estrato más pobre, sin que la brecha de desigualdad experimentara cambios. Justamente, para esta población el riesgo ambiental se redujo solo de $43,3 \%$ a $39,6 \%$, mientras que en el extremo opuesto de la estratificación social el nivel de déficit se mantuvo siempre por debajo del $16 \%$ sin diferencias significativas.

\section{Acceso a Recursos Psicosociales}

Los recursos psicosociales con los que cuenta la población argentina constituyen algo más que indicadores de calidad de vida, son también indicadores directos de acceso a recursos y capacidades de desarrollo humano y de integración social. En el 
presente apartado se analiza la evolución entre 2004 y 2012 de diferentes variables psicosociales seleccionadas y su relación con la posición social de las personas de 18 años o más (Cuadro 5).

Existen recursos personales que representan aspectos subjetivos del desarrollo humano, cuya evolución puede verse obstaculizada por un contexto desfavorable, ya que los rasgos y atributos psicológicos se modelan socialmente. En tal sentido, es esperable que las situaciones sostenidas de vulnerabilidad social dificulten los logros personales y afecten el bienestar individual. Para analizar este aspecto se evalúan diferentes tipos de recursos y riesgos psicosociales. En primer lugar, a nivel de los recursos, se examina el malestar psicológico, la inexistencia de proyecto personal y la falta de apoyo social. En este punto los resultados refieren a variables cognitivas y emocionales. En segundo lugar, en cuanto a riesgos sociales de alto impacto psicológico, se considera el experimentar discriminación y el haber sido víctima de un delito.

Cuadro 5. Recursos psicológicos y vida social (18 años o más). EDSA total urbano. Años: 2004, 2007, 2010 y 2012. ${ }^{1}$ en porcentajes.

\begin{tabular}{|c|l|c|c|c|c|}
\hline & & $\mathbf{2 0 0 4}$ & $\mathbf{2 0 0 7}$ & $\mathbf{2 0 1 0}$ & $\mathbf{2 0 1 2}$ \\
\hline \multirow{4}{*}{$\begin{array}{c}\text { Malestar } \\
\text { psicológico }\end{array}$} & Total & $\mathbf{2 3 , 8}$ & $\mathbf{2 0 , 4}$ & $\mathbf{1 9 , 0}$ & $\mathbf{2 0 , 1}$ \\
\cline { 2 - 6 } & (1) Muy Bajo & 26 & 26 & 28,2 & 31,2 \\
& (2) Medio - Alto & 24 & 17,1 & 7,5 & 10,2 \\
& Ratio (1) / (2) & 1,1 & 1,5 & 3,8 & 3,1 \\
\hline \multirow{4}{*}{$\begin{array}{c}\text { Déficit de apoyo } \\
\text { social }\end{array}$} & Total & $\mathbf{4 5 , 6}$ & $\mathbf{2 8 , 3}$ & $\mathbf{3 3 , 5}$ & $\mathbf{3 2 , 7}$ \\
\cline { 2 - 6 } & (1) Muy Bajo & 65,2 & 37,3 & 42,4 & 41,5 \\
\cline { 2 - 6 } & (2) Medio - Alto & 25,2 & 20,4 & 22,0 & 24,9 \\
\cline { 2 - 6 } & Ratio (1) / (2) & 2,6 & 1,8 & 1,9 & 1,6 \\
\hline \multirow{4}{*}{$\begin{array}{c}\text { Péficit de } \\
\text { Peroyectos }\end{array}$} & Total & $\mathbf{2 2 , 0}$ & $\mathbf{1 6 , 7}$ & $\mathbf{1 6 , 2}$ & $\mathbf{1 3 , 9}$ \\
\cline { 2 - 6 } & (1) Muy Bajo & 36,7 & 25,1 & 24,7 & 23,1 \\
\cline { 2 - 6 } & (2) Medio - Alto & 11,9 & 5,8 & 5,4 & 5,9 \\
\cline { 2 - 6 } & Ratio (1) / (2) & 3,1 & 4,3 & 4,6 & 3,9 \\
\hline \multirow{3}{*}{$\begin{array}{c}\text { Haber sido } \\
\text { víctima de un } \\
\text { delito }\end{array}$} & Total & $\mathbf{2 0 , 7}$ & $\mathbf{2 2 , 1}$ & $\mathbf{2 8 , 4}$ & $\mathbf{3 0 , 3}$ \\
\cline { 2 - 6 } & (1) Muy Bajo & 14,8 & 15,5 & 22,2 & 20,0 \\
\cline { 2 - 6 } & (2) Medio - Alto & 20,8 & 27,9 & 33,7 & 35,8 \\
\cline { 2 - 6 } & Ratio (1) / (2) & 0.7 & 0.5 & 0.7 & 0.6 \\
\hline \multirow{3}{*}{$\begin{array}{c}\text { Sentirse } \\
\text { discriminado }\end{array}$} & Total & $\mathbf{1 2 , 7}$ & $\mathbf{7 , 8}$ & $\mathbf{1 2 , 3}$ & $\mathbf{1 2 , 9}$ \\
\cline { 2 - 6 } & (1) Muy Bajo & 21,4 & 9,1 & 15,0 & 16,3 \\
\cline { 2 - 6 } & (2) Medio - Alto & 11,9 & 6,3 & 10,0 & 9,8 \\
\cline { 2 - 6 } & Ratio (1) / (2) & 1,8 & 1,4 & 1,5 & 1,7 \\
\hline
\end{tabular}

${ }^{1}$ Con el objetivo de hacer comparables los datos de la EDSA Bicentenario 2010-2012 con serie anterior (EDSA 2004-2010), los datos correspondientes a 2004 y 2007 fueron ajustados por un coeficiente de empalme con base en el año 2010. 
Fuente: EDSA $2004-2010$ ( $n=2.100$ hogares) y EDSA-Bicentenario 2010-2016 ( $n=5.700$ hogares), Observatorio de la Deuda Social Argentina, UCA.

Malestar psicológico. El malestar psicológico constituye un déficit en las capacidades emocionales y cognitivas de las personas para responder a demandas ordinarias de la vida cotidiana, desenvolverse socialmente y tener relaciones satisfactorias con los otros. Con el fin de medir este padecimiento, la EDSA aplica una escala que evalúa el estado de salud mental general conocida como KPDS-10 (por sus siglas en inglés, Kessler Psychological Distress Scale). La versión abreviada del instrumento que se aplica en la EDSA cuenta con diez ítems que miden un conjunto de síntomas relacionados con depresión y ansiedad tales como la desesperanza, la tristeza, el nerviosismo y el cansancio. Los resultados obtenidos aportan una aproximación al malestar psicológico, sin determinar un trastorno específico de depresión o ansiedad. ${ }^{13}$

Al igual que en otras dimensiones, los cambios más importantes ocurridos en esta variable tuvieron lugar entre 2004 y 2007, el mejor momento socio-económico de la década, pasando el indicador de 23,8\% a 20,4\%. A partir de ese momento y hasta 2012 , la prevalencia de malestar psicológico se estabiliza, alcanzando un 20,1\% de la población en 2012. Ahora bien, el dato que sin duda llama especialmente la atención es que, para el caso de la población del estrato más pobre, los síntomas de desesperanza, tristeza, nerviosismo y cansancio se habrían mantenido constantes entre 2004-2007, afectando al 26\% de esa población, para luego llegar a 30,1\% en 2012. Durante ese mismo lapso, en la población del estrato medio alto se observó una caída acentuada a lo largo de todo el período, pasando de 24,0\% en 2004 a 10,2\% en 2012. Por ello, de no existir casi diferencias sociales estructurales al inicio de la serie, estas se triplicarían durante la segunda parte de la década.

Déficit de apoyo social. Las redes de ayuda mutua representan un importante punto de referencia para las personas, dado que representan una fuente para la resolución de problemas de la vida cotidiana. La importancia que tienen estas redes se centra en los efectos positivos sobre el sentimiento de seguridad y de bienestar que notan los sujetos. En el caso de que el individuo no tenga acceso a los recursos que ofrecen las redes interpersonales, disminuye la percepción que tiene de hacer frente a los problemas por sus propios medios, al tiempo que su salud mental declina, pues los altos niveles de estrés que generan las situaciones de riesgo afectan al desarrollo de sus habilidades sociales. Ello provoca en el sujeto una percepción de incapacidad para mantener relaciones seguras y reduce sus capacidades de lograr el apoyo social requerido. De esta manera, la existencia o no de otros en condiciones de brindar ayuda

\footnotetext{
${ }^{13}$ La KPDS-10 se responde teniendo en cuenta cómo se sintió el entrevistado en el último mes, en una escala tipo Likert de cinco puntos (todo el tiempo, la mayor parte del tiempo, a veces, pocas veces y nunca).
} 
personal se constituye en un factor clave de bienestar o malestar subjetivo.

A fin de indagar acerca del apoyo social percibido, en la EDSA se incluyó el siguiente ítem: "Ante un problema, cuento con gente que me puede ayudar a resolverlo". Este ítem se responde con una escala de cinco opciones, que van de "casi siempre" a "casi nunca". ${ }^{14}$ El déficit de apoyo social percibido partió de niveles particularmente elevados en la post-crisis, cayendo de manera significativa en 2007 (de 45,6\% a 28,3\%), para luego volver a aumentar durante los años siguientes. En 2012, el 32,7\% de la población adulta urbana percibía no contar con otros que pudieran ayudarlo a resolver problemas. El análisis por estrato social, comparando los años 2004 y 2012, muestra que tanto el estrato muy bajo como el medio alto repiten la tendencia anterior: una fuerte disminución, entre 2004 y 2007, y un posterior aumento en 2010 y 2012, aunque en ambos casos, los cambios más marcados tuvieron lugar en el segmento más pobre de la estratificación social. De esta manera, a nivel de balance 2004-2012 se puede apreciar que en el estrato más bajo el déficit pasó de $65,2 \%$ a $41,5 \%$, mientras que en el estrato medio alto casi no experimentó cambios (pasó de $25,2 \%$ a $24,9 \%$ ). En cualquier caso, luego de una primera reducción de la brecha de déficit entre la población de ambos estratos, la misma se ha mantenido en casi el doble de riesgo para los sectores más vulnerables.

Déficit de proyecto personal. En la misma línea con el enfoque del desarrollo humano, cabe esperar que en una sociedad en desarrollo los individuos sean agentes de sus propias vidas. Los proyectos de vida involucran el proceso mental mediante el cual las personas sienten que pueden alcanzar las metas que se proponen y en consecuencia, lograr una percepción de autonomía.

Así, las aspiraciones constituyen una categoría abarcadora para comprender de qué manera las personas integran diferentes fuentes de influencia (biológicas, ambientales, sociales y culturales) para dar coherencia y balance a la propia vida. En este sentido, el bienestar se logra en la medida en que las personas pueden percibir, estructurar y dar un significado a los proyectos personales, lo cual aumenta las probabilidades de realización. Por el contrario, la baja sensación de autonomía y de satisfacción está relacionada con proyectos personales no significativos y desorganizados. ${ }^{15}$

En este caso, de la misma manera que en la variable de falta de apoyo social, la reducción más importante del déficit tuvo lugar entre 2004 y 2007 (de 22\% a 16,7\%). A partir de allí la situación se estanca en un nivel cercano al 16\% que se mantiene hasta el final del período. En términos de diferencias sociales se observa que ambos estratos

\footnotetext{
${ }^{14}$ Cabe señalar que se analiza la percepción de falta de apoyo social, es decir la sensación intrínseca de que no se cuenta con la ayuda de otros para resolver problemas, y no la ayuda efectivamente recibida o no de otras personas.

${ }^{15}$ En la EDSA se incluye una pregunta para indagar sobre la percepción que tienen las personas de poder plantearse proyectos personales a futuro: “¿Usted, puede pensar proyectos más allá del día a día?". Los entrevistados indicaron en un formato de respuesta dicotómico, si el enunciado resultaba verdadero o falso.
} 
experimentaron la misma tendencia general: inicial caída en el déficit (2004-2007) y posterior estancamiento de la prevalencia (2007-2010), aunque con tasas de incidencia muy diferentes: por ejemplo, en 2012 , el 23,1\% de la población del estrato muy bajo sufría ausencia de proyecto contra apenas un 5,9\% en el estrato medio alto.

Riesgo a ser víctima de delito. La inseguridad es uno de los problemas sociales que más preocupan a la opinión pública, constituyendo un aspecto fundamental para el desarrollo de la vida ciudadana. El problema no es menor: ser víctima de un delito o acto de agresión tiene un efecto negativo directo sobre la calidad de vida, la autonomía personal y el bienestar subjetivo, así como sobre las capacidades de integración social. Al mismo tiempo, son diversos los tratados internacionales que reconocen el derecho a la seguridad e integridad corporal como un derecho humano fundamental.

El riesgo de ser víctima de un delito se mide en este caso por auto percepción de la persona adulta, sea que ella declare haber sufrido un delito en forma personal, o que lo haya sido algún miembro del hogar, al menos una vez durante los últimos doce meses. A partir de este indicador se observa que los niveles de victimización aumentaron desde 2004, pero de manera mucho más sostenida después de 2007. En efecto, este indicador pasó de una tasa de delito de 20,7\% al inicio de la serie, a 22,1\% en 2007 y, a partir de ese momento, a 28,4\% en 2010 y 30,3\% en 2012.

Esta tendencia se reproduce tanto en la población adulta del estrato muy bajo como en la población del estrato medio alto. En el primero, la victimización creció de 14,8\% en 2004 a 20,0\% en 2012, mientras que en el segundo aumentó de 20,8\% a 35,8\%, respectivamente. En todos los años las cifras de victimización son más altas para el segmento medio-alto, pero sin que ello permita afirmar que sean los sectores más pobres los más protegidos. Por el contrario, se sabe que, debido justamente a la mayor vulnerabilidad general, es en estos sectores donde el delito registra un mayor impacto absoluto.

Sufrir discriminación. La discriminación puede ser entendida como un comportamiento negativo dirigido hacia a miembros de un grupo diferente al propio sobre el cual se ejerce un prejuicio (Dovidio y Gaertner, 1986). Por lo general, el concepto describe aquellas situaciones en donde se da un trato de inferioridad a una persona, grupo o colectividad por motivos de raza, apariencia física, nacionalidad, religión, género, nivel socioeconómico, ocupación y/o lugar de residencia, entre otros motivos posibles. El discriminar es un acto que atenta contra la igualdad de oportunidades y derechos, y que como tal es nacional e internacionalmente sancionado en todas sus formas.

Para el período analizado destaca el hecho de la estabilidad que registra la tasa de discriminación, la cual se mantuvo en todos los años por debajo del 13\%. En este marco, el comportamiento de este riesgo social muestra una situación estructural de 
desventaja para los estratos más pobres. Entre puntas de la serie, la tasa de percepción de discriminación para esta población pasó de $21,4 \%$ a $16,3 \%$, mientras que en el segmento medio-alto la tasa pasó de $11,9 \%$ a 9,8\%.

\section{Conclusiones}

La crisis de 2001-2002 profundizó la deuda social en la Argentina, sumando una nueva generación de pobres y una mayor desigualdad, pero rápidamente un continuo proceso de expansión económica permitió recuperar la demanda de empleo y mejorar las condiciones de vida de gran parte de la población. Sin embargo, más de una década de crecimiento no ha sido suficiente para resolver los problemas de marginalidad estructural que afectan al menos a uno de cada cuatro argentinos. Estamos hablando de familias en situación de pobreza estructural que aunque han ganado "derechos", no pueden acceder a un empleo de calidad ni a un hábitat digno, tampoco a servicios de salud ni de educación satisfactorios. Son sectores que solo logran contar con la asistencia social del Estado a través de programas de transferencia de ingresos, los cuales no permiten salir de la condición de exclusión estructural.

En efecto, a pesar de los conocidos avances alcanzados en materia de derechos económicos y sociales, así como de las mejoras logradas durante la última década en el nivel de empleo e ingresos de las familias -sobre todo en los asalariados formales y las clases medias-, es evidente que todavía no existen condiciones de inclusión social para todos. Por este motivo, la persistente desigualdad social se constituye en una barrera al desarrollo. A esto se suma la evidente ausencia de políticas estratégicas orientadas a lograr -de manera intergeneracional y sustentable- una efectiva inclusión social de los sectores que se encuentran marginados.

En la situación más extrema, y aunque nuestro país constituye uno de los principales productores mundiales de alimentos, todavía uno de cada diez hogares urbanos (más de tres millones de personas) experimenta malnutrición. Esto ocurre como consecuencia de no disponer de los recursos económicos suficientes para acceder a los alimentos necesarios para una nutrición adecuada. La situación pone en evidencia la insuficiencia de las políticas de transferencia de ingresos como mecanismo para garantizar el derecho de la población no solo a una adecuada alimentación, sino también a una efectiva participación económica, social y política en igualdad de condiciones. Los programas de transferencia de ingresos -tal como la Asignación Universal por Hijo- logran cubrir las necesidades económicas más urgentes pero no constituyen una plataforma efectiva para erradicar la marginalidad estructural en materia de nutrición, salud, educación, vivienda, empleo, seguridad social y ciudadanía.

Al respecto, cabe destacar que aún hoy persiste un $8 \%$ de desempleo y casi la mitad 
de los trabajadores ocupados tiene un empleo precario. Asimismo, más de la mitad de las nuevas generaciones de adultos está excluida del sistema de la seguridad social. En este marco, no debe sorprender que la pobreza urbana medida por los ingresos, afecte todavía a no menos del $25 \%$ de la población urbana (10 millones de personas), que una de cada 10 viviendas no cuente con agua corriente y que tres de cada 10 no dispongan de servicio de cloacas. Entretanto, el $37 \%$ de los jóvenes no logra terminar la secundaria, el $20 \%$ no estudia ni trabaja y el $12 \%$ de los niños de entre 5 y 17 años debe realizar alguna actividad laboral para cubrir necesidades económicas del hogar. De ahí también la necesidad de que dos de cada 10 hogares requieran de asistencia pública de manera permanente, y que a pesar de este esfuerzo fiscal, uno de cada cuatro hogares urbanos (alrededor de 10.000.000) no alcanza ingresos suficientes para cubrir el valor de una canasta básica de bienes y servicios para el funcionamiento social de base/mínimo.

Aun así la principal complejidad es que la profundidad del déficit social no solo no es menor sino que el problema no parece ser transitorio. Una vez pasada la recuperación económica postcrisis durante la primera parte de la década pasada, expandido el mercado interno y multiplicado el empleo, las desigualdades estructurales se mantienen casi sin cambios. Esto incluso a pesar de que la economía haya logrado recuperarse rápidamente en 2010-2011 de la crisis internacional, sirviéndose para ello del aumento del consumo interno, la inversión pública y el gasto social, es decir, no sin mejoras objetivas en materia social, aunque parciales debido al proceso inflacionario y el débil impacto de estos procesos sobre la creación de empleos productivos.

En este sentido, la experiencia histórica de nuestro país, durante las pasadas dos décadas, confirma una teoría para las economías capitalistas subdesarrolladas cada vez más aceptada: el crecimiento no genera un desarrollo socioeconómico sustentable cuando su propia reproducción genera una "población sobrante" que el modelo económico y de organización político-institucional no es capaz de integrar productiva, social ni culturalmente. Las desigualdades estructurales que emergen en este contexto dan forma a una matriz social fragmentada, conflictiva, violenta, débil en reglas de convivencia democrática. En este marco, a pesar de que este país y parte de su sociedad son hoy más ricos que hace diez años -tanto en recursos económicos como en derechos sociales- otra parte de la sociedad continúa privada de condiciones básicas para el desarrollo humano y la integración ciudadana. Es sobre estas bases que se reproducen determinados patrones de marginalidad social, a la vez que se potencian sus efectos en materia de ilegalidad, inseguridad y violencia.

Ante este cuadro de realidad, cabe preguntarse ¿qué hacer? ¿Cómo salir de las trampas que impone un modelo de crecimiento que reproduce condiciones de exclusión? ¿Cuáles son los cambios necesarios que debe afrontar esta sociedad en 
función de comenzar a superar las barreras que frenan el desarrollo, la convergencia y la integración social? Una parte de la respuesta está en la economía. Teniendo en cuenta los desafíos que impone la década en curso, es momento de reconocer que el actual modelo económico y la inflación asociada no han sido capaces de generar los empleos productivos necesarios ni suficientes para dar cabida, aprovechar y hacer posible la inclusión económica de toda la población. La situación exige políticas de estabilización con crecimiento y protección social, pero también un programa nacional de desarrollo socioeconómico, una fuerte movilización de inversiones y una integral reforma del Estado.

Ahora bien, la otra parte de la respuesta no es menos compleja, en tanto que cabe poner en el centro de la escena el papel de la política. ¿Qué responsabilidad les cabe en esta historia a las clases dirigentes, a las instituciones democráticas y a la propia opinión pública? En su conjunto, estos factores han mostrado ser incapaces de establecer proyectos estratégicos y acuerdos en función de un horizonte democrático con seguridad jurídica, inclusión social y equidad distributiva. En este sentido, quizás el principal problema sea la falta de un bloque social de poder con voluntad política para promover un programa estratégico de desarrollo, capaz de movilizar al conjunto de los recursos materiales y humanos de que dispone el país alrededor de una política que transforme las pautas distributivas del crecimiento y fomente un efectivo progreso social en los sectores más pobres.

Sin duda, es también momento de salir de esta trampa, pero para hacerlo no es suficiente un cambio de gobierno. Para salir del estado de pobreza que reproduce este modelo económico se requiere, en efecto, de una apuesta diferente por parte de las nuevas dirigencias hacia un cambio de rumbo, pero también una opinión pública menos dócil, más memoriosa y más comprometida con políticas de Estado que garanticen una ciudadanía plena para todos en un marco de mayor justicia y equidad. Obviamente, el problema resulta aún más complicado cuando es el propio gobierno el que carece de y/u oculta las estadísticas económicas y sociales del país real.

\section{Bibliografía}

Arza, C. (2002). La privatización de los servicios públicos y sus impactos distributivos. En D. Azpiazu (comp.). Privatizaciones y poder económico. Buenos Aires: UNQUI.

Banco Mundial (2000). Informe sobre el desarrollo mundial. Washington DC: Banco Mundial

CENDA (Centro de Estudios para el Desarrollo Argentino) (2010). La anatomía del nuevo patrón de crecimiento y la encrucijada actual. La economía argentina en el período 2002-2010. Buenos Aires: Editorial Cara o Ceca. 
Damill, M. y Frenkel, R. (2011). Macroeconomic policies and performances in Latin America 1990-2010, CEDES, Buenos Aires, December.

Donza, E. (2011). Trabajo productivo y trabajo reproductivo. Inequidades y cumplimiento de derechos. En Salvia et al. Barómetro de la Deuda Social Argentina del Bicentenario. Serie del Bicentenario (2010-2016), Año I. Buenos Aires: ODSA, UCA, pp. 89-134.

Donza, E. (2012). Satisfactores laborales y protección social. En Salvia et al. Barómetro de la Deuda Social Argentina del Bicentenario. Serie del Bicentenario (2010-2016), Año II. Buenos Aires: ODSA, UCA, pp. 133-176.

Dovidio, J. y Gaertner, S.L. (1986). Prejudice, discrimination and racism: Historical trends and contemporary approaches. En Puerías Valdeiglesias, S. (2004), Seminario México, Año 2004, vol. 56, nº 2, pp. 135-144.

INDEC (2012). Mercado de trabajo: Principales Indicadores. En Informes de prensa de la Encuesta Permanente de Hogares, $1^{\circ}$ y $2^{\circ}$ trimestre de 2004-2012. Buenos Aires: Ministerio de Economía de la Nación.

INDEC (2012). Evolución de la distribución del ingreso. En Informes de prensa de la Encuesta Permanente de Hogares. Buenos Aires: Ministerio de Economía de la Nación.

ONU (1996). Segunda Conferencia de las Naciones Unidas sobre Asentamientos Humanos (Hábitat II). Recuperado de http://habitat.aq.upm.es/aghab/.

Pychyl, T. A. y Little, B. R. (1998). "Dimensional specificity in the prediction of subjective well-being: Personal Projects in pursuit of the PhD". Social Indicators Research, vol. 45, pp. 423-473.

Renkel, R., el al. (2011). "Regulaciones financieras y macroeconomía: la experiencia paradigmática de la Argentina en los años noventa" en Desarrollo Económico No 200 Vol. 50, enero-marzo 2011. Buenos Aires.

Salvia, A. y Tami, F. (2005). Introducción: desarrollo humano y deuda social. En Salvia, A. y Tami, F. (coord.). Barómetro de la Deuda Social Argentina, Año I, Las grandes desigualdades. Buenos Aires: ODSA, UCA.

Salvia, A. (2011a). El desarrollo humano y social desde una perspectiva de derechos. El país real al inicio del Bicentenario (2010-2016). En Barómetro de la Deuda Social Argentina del Bicentenario, Serie del Bicentenario, Año I. Estado de situación del desarrollo humano y social. Buenos Aires: ODSA, UCA.

Salvia A. (2011b). La Trampa Neoliberal. Nueva Marginalidad, Desigualdad Económica y Reformas Estructurales en la Argentina: 1990-2003. Buenos Aires: EUDEBA. ISBN 978-950-23-1882-0. 